\title{
COMPARISON OF THE ADAPTATION TO PREGNANCY IN WOMEN WHO RECEIVED INFERTILITY TREATMENT AND THOSE WHO DIDN'T
}

\author{
Hazal Aksu', Duygu Gulec Satir ${ }^{2}$ \\ ${ }^{1}$ University of Health Sciences, Izmir Bozyaka Education and Research Hospital, Izmir, Turkey \\ ${ }^{2}$ Ege University, Faculty of Nursing, Izmir, Turkey \\ Corresponding Author: Duygu Gulec Satir, Asst. Prof., E-mail: duygugulec50@hotmail.com \\ Received: 07.10.2021; Accepted: 09.01.2022; Available Online Date: 27.01.2022 \\ CCopyright 2021 by Dokuz Eylül University, Institute of Health Sciences - Available online at https://dergipark.org.tr/en/pub/jbachs
}

Cite this article as: Aksu H, Gulec-Satir D. Comparison of the Adaptation to Pregnancy in Women Who Received Infertility Treatment and Those Who Didn't. J Basic Clin Health Sci 2022; 6: 260-267.

\begin{abstract}
Purpose: It was aimed to compare the adaptation to pregnancy in women who received infertility treatment and those who didn't.

Methods: A total of 174 pregnant women were included in the study, 51 in the group that received infertility treatment and 123 in the group that did not. The data were collected with the Personal Information Form including the descriptive characteristics and the Prenatal Self-Evaluation Questionnaire (PSEQ).

Results: The mean age of the pregnant women who received infertility treatment was $33.73 \pm 5.79$ years, while it was $28.89 \pm 4.12$ years for those who didn't. Although the mean total score of PSEQ was lower in pregnant women receiving infertility treatment, the difference was not found to be statistically significant. In the group that became pregnant with the infertility treatment, the subdimension score of "thoughts about the well-being of self and baby" was found to be higher, while the scores of subdimensions "identification with motherhood role ", "readiness for labour" and "control in labour" were lower.

Conclusion: In the study, the adaptation to the pregnancy of both groups was found to be similar. On the other hand, pregnant women who received infertility treatment were found to have lower adaptation to the thoughts about the wellbeing of self and baby sub-dimension, and higher adaptation to the identification with the role of motherhood, preparation for labour and control in labour subdimensions.
\end{abstract}

Keywords: Infertility, assisted reproductive techniques, woman, compliance with pregnancy, adaptation

\section{INTRODUCTION}

Infertility is an important health problem that affects women's quality of life significantly and has consequences such as stress, social stigma, social isolation and incompatibility in marriage $(1,2)$. Its incidence, varying according to countries, is $6 \%$ in the USA, $25 \%$ in China, $5 \%$ in Iran, and $8.1 \%$ in Turkey (3-6).
The infertility treatment process is a non-stationary process in which different treatments and interventions are applied (7). During this process, women may experience disappointment due to unsuccessful results and experience complex problems ranging from physiological, psychological, social and ethical areas (8-10). A successful outcome of infertility treatment is the dream of every woman. 
With the development of assisted reproductive techniques, the sense of uncertainty and waiting that many women have experienced for many years can result in pregnancy. With the treatment resulting in pregnancy, individual and social problems that have been going through for a long term are not solved at once. Pregnancy, expected to be a happy and enjoyable period, can turn into an adventure accompanied by feelings of anxiety, fear and despair (11). Furthermore, the feeling of losing control over their body due to getting pregnant with assisted reproductive techniques may carry over during pregnancy and childbirth. Women may also experience the feeling that they cannot control pregnancy (12). Cavusoglu and Beji (2014) reported in their study that the quality of life of pregnant women after infertility treatment is more negatively affected in mental health, physical function and physical role sub-dimensions than women who became pregnant spontaneously (13).

In addition to psychological changes, physical changes are also experienced in pregnancies that occur after infertility treatments. In these pregnant women, many complications such as multiple pregnancy, fetal reduction, high-risk pregnancy, preterm birth, low birth weight can be observed (1416). In this process, expectant mothers both try to adapt to pregnancy and prepare themselves for motherhood, while focusing on maintaining a healthy pregnancy along with the physical and psychological changes they experience.

Adapting to pregnancy and motherhood positively affects women's self-confidence and life satisfaction in the postpartum period, making it easier for them to adapt to the role of motherhood and the postpartum period (17). It is thought that it is important to investigate the adaptation to the pregnancy of women who became pregnant after a difficult process such as infertility treatment in order for them to have a healthy pregnancy, birth and postpartum period, and to evaluate whether their adaptation is different from women who become pregnant naturally. In line with this, this study was carried out to compare the adaptation to pregnancy in women who received infertility treatment and those who didn't.

\section{METHODS}

This comparative descriptive design study was conducted online between February and April 2021.

\section{Population and Sample of the Study}

Since face-to-face interviews could not be conducted due to the COVID-19 pandemic, the population of the study consisted of pregnant women over the age of 18 , who actively followed infertility and pregnancyrelated pages/groups on social media (Facebook, Instagram), became pregnant after receiving infertility treatment or without receiving infertility treatment. $G^{*}$ Power Version 3.1.9.2 was used to determine the sample size. The number of pregnant women that should be included in the sample of the study was calculated as at least 51 for the group who became pregnant with infertility treatment and at least 116 for the group who got pregnant naturally, by using the mean scores of the scales in Başgöl and Beji (2018)'s thesis study, the $d=0.41$ effect power was calculated with the t-test, $\alpha=0.05$, to reach $80 \%$ power in the $95 \%$ confidence interval (18). Data collection was continued until a total of 51 pregnant women who met the inclusion criteria and had a pregnancy after infertility treatment have been reached.

Being over the age of 18 , being literate, using the internet and social media, being in the 14-41 weeks of pregnancy and participating voluntarily in the study were determined to be the criteria for inclusion. Those with health problems in the fetus and psychiatric disorders diagnosed during the pregnancy were excluded from the study.

\section{Data Collection Method and Data Collection Tools}

Data were collected online to minimize the risk of transmission due to the COVID-19 pandemic. The data were collected with the Personal Information Form including the descriptive characteristics of the pregnant women and the Prenatal Self-Evaluation Questionnaire (PSEQ). Data collection forms created online via Google Forms were shared with pregnant women who actively followed pages/groups related to infertility and pregnancy on Facebook and Instagram, and they were invited to participate in the study.

\section{Personal information form was prepared in line with} the literature $(8,16)$. It consists of questions including sociodemographic (age, education level, employment status, income perception, family type) and obstetric (week of gestation, multiple pregnancy status, number of pregnancies, number of births, number of miscarriages, number of living children, type of pregnancy, experiencing problems during pregnancy, 
Table 1. Comparison of the descriptive characteristics of pregnant women who received infertility treatment and those who did not

\begin{tabular}{|c|c|c|c|c|c|}
\hline \multirow[b]{2}{*}{ Characteristics } & \multicolumn{2}{|c|}{$\begin{array}{l}\text { Not Receiving Infertility } \\
\text { Treatment (n:123) }\end{array}$} & \multicolumn{2}{|c|}{$\begin{array}{l}\text { Receiving Infertility } \\
\text { Treatment (n:51) }\end{array}$} & \multirow{2}{*}{$\begin{array}{l}\text { Statistics } \\
\chi^{2 / p}\end{array}$} \\
\hline & Number & Percentage & Number & Percentage & \\
\hline \multicolumn{6}{|l|}{ Age group } \\
\hline Below 30 & 83 & 67.5 & 14 & 27,5 & 23,416 \\
\hline 30 years and above & 40 & 32.5 & 37 & 72,5 & 0,001 \\
\hline \multicolumn{6}{|l|}{ Education level } \\
\hline High school and below & 36 & 29.3 & 23 & 45.1 & 11.720 \\
\hline University & 77 & 62.6 & 18 & 35.3 & 0.003 \\
\hline Graduate & 10 & 8.1 & 10 & 19.6 & \\
\hline \multicolumn{6}{|l|}{ Gestational week } \\
\hline $13-27$ & 59 & 49.0 & 22 & 43.1 & 0.338 \\
\hline $28-40$ & 64 & 52.0 & 29 & 56.9 & 0.561 \\
\hline \multicolumn{6}{|l|}{ Multiple pregnancy } \\
\hline Yes & 5 & 4.1 & 10 & 19.6 & 11.056 \\
\hline No & 118 & 95.9 & 41 & 84.6 & 0.001 \\
\hline \multicolumn{6}{|l|}{ Number of pregnancies } \\
\hline 1 & 79 & 62.7 & 19 & 37.3 & 10.662 \\
\hline 2 or more & 44 & 37.3 & 32 & 62.7 & 0.001 \\
\hline \multicolumn{6}{|l|}{ Number of births } \\
\hline 0 & 67 & 54.5 & 44 & 86.3 & 15.787 \\
\hline 1 or more & 56 & 45.5 & 7 & 13.7 & 0.001 \\
\hline \multicolumn{6}{|c|}{ Number of children living } \\
\hline \multicolumn{6}{|c|}{0} \\
\hline 1 or more & 77 & 62.6 & 47 & 92.2 & 15.378 \\
\hline & 46 & 37.4 & 4 & 7.8 & 0.001 \\
\hline \multicolumn{6}{|l|}{ Number of miscarriage } \\
\hline 0 & 101 & 82.1 & 19 & 39.2 & 37.543 \\
\hline 1 & 15 & 12.2 & 14 & 27.5 & 0.001 \\
\hline 2 or more & 7 & 5.7 & 18 & 33.3 & \\
\hline
\end{tabular}

experienced problems, admittance to hospital status) characteristics.

PSEQ was developed by Lederman (1979) to evaluate the adaptation of women in the prenatal period to pregnancy and motherhood (19). Its adaptability to the Turkish language was performed by Beydağ and Mete (2008) in 2008 (20). The 4-point Likert-type scale, consisting of a total of 79 items, has seven subdimensions. These subdimensions were grouped as the well-being of self and baby, acceptance of pregnancy, identification with motherhood role, preparation for labour, control in labour, relationship with mother and relationship with the partner. The minimum score that can be obtained from the scale is 79 , and the maximum score is 316 . Low scores obtained from the scale indicate a high level of adaptation to pregnancy $(19,20)$. In the adaptation of the scale, the internal consistency reliability coefficient for the whole scale was high $(\alpha=0.81)$, and it was found to be between 0.72 and 0.85 for the subdimensions (20). In this study, Cronbach's alpha coefficient was found to be 0.91 for the whole scale, while it was between 0.70 and 0.92 for the subdimensions.

\section{Statistical analysis}

The Statistical Package for Social Sciences (SPSS) 24.0 package program was used for the analysis of the data. Descriptive analyses (number, percentage, mean and standard deviation) were calculated to determine the descriptive characteristics. Pearson's Chi-Square test was used in cases where the sample size assumption was met, and Fisher's Exact Test was used in cases where it was not, to compare the descriptive characteristics of pregnant women who received infertility treatment and those who didn't. Since the data did not show a normal distribution (Kolmogorov Smirnov $p<0.05$ ), the Mann Whitney-U test and the Kruskal Wallis test were used to compare the descriptive characteristics of the groups with the scale score. The Mann Whitney-U test was used to compare the scale scores of the two groups. In the study, the statistical significance level was considered as $p<0.05$ with a $95 \%$ confidence interval. 
Table 2. Comparison of the findings on the health status of pregnant women who received infertility treatment and those who did not

$$
\begin{aligned}
& \text { Not Receiving Infertility } \\
& \text { Treatment (n:123) } \\
& \text { Number Percentage }
\end{aligned}
$$

$$
\text { Receiving Infertility }
$$$$
\text { Treatment (n:51) }
$$

Number Percentage
Statistics

$\chi 2 / p$

\section{Experiencing problem}

Yes

No

The experienced problem

Nausea

Risk of miscarriage

EDT

GDM

Hypertension

Oligohydramnios

Infection

(Covid, UTI, Toxo)

Other(Allergies, anaemia,

cholestasis)

\section{3}

90

\section{9}

10

4

2

1

$-$

5

6

\section{8}

73.2

7.3

8.1

3.3

1.6

0.8

4.1

4.9

\section{Admittance to hospital}

Yes

9

No

76.5

23.5

36.625

0.001

$\begin{array}{lll}39 & 76.5 & 36.625 \\ 12 & 23.5 & \mathbf{0 . 0 0 1}\end{array}$

114

\section{3}

92.7
-

21.6

13.7

39.2

5.9

$3 \quad 5.9$

\section{Ethical Aspects}

In the first stage of data collection, the informed consent form link which explained the purpose and content of the study was clicked on by the participants and the consent of the volunteers was obtained before proceeding to the questionnaire. Permission was obtained from the authors who adapted the PSEQ to Turkish to use the scale, and approval was obtained from the University's Clinical Research Ethics Committee (Date: 18.02.2021/No: 212.1.T/70) to conduct the study.

\section{RESULTS}

In the study, the mean age of the pregnant women who received infertility treatment was $33.73 \pm 5.79$ years, $45.1 \%$ of them had an education level of high school or below, $54.9 \%$ were employed, $37.3 \%$ had their first pregnancy. On the other hand, the mean age of those who did not receive infertility treatment was $28.89 \pm 4.12$ years, $62.6 \%$ were university graduates, $54 \%$ were employed and $62.7 \%$ had their first pregnancy. The majority of them in both groups stated their income equal to their expenses, and family type as a nuclear family, while the other individual characteristics are given in Table 1.
According to the study results, a statistically significant difference was found between the pregnant women in the two groups in terms of age group, education level, multiple pregnancies, number of pregnancies, number of births, number of living children and number of miscarriages $(p<0.05)$. The age, number of multiple pregnancies, history of two or more pregnancies and miscarriages were found to be higher in the group receiving infertility treatment, while the number of births of one or more and the number of living children was lower than the other group. In pregnant women receiving infertility treatment, the rate of women with high school and lower education levels was found to be higher (Table 1).

In the study, $76.5 \%$ of the pregnant women who received infertility treatment were found to have problems and $56.9 \%$ of them were admitted to hospital during pregnancy. While $73.2 \%$ of the pregnant women who did not receive infertility treatment did not have problems and $92.7 \%$ of them were not admitted to hospital during pregnancy. There was a statistically significant difference between the groups in terms of experiencing problems during pregnancy and admittance to 
hospital, while pregnant women who received infertility treatment were found to experience significantly more health problems and were admitted to hospital more often $(p<0.05)$ (Table 2).

The PSEQ total score and other subdimension scores of both groups in the study are given in Table 3. A statistically significant difference was found between the groups in terms of the scores of subdimensions "Thoughts about the wellbeing of self and baby, identification with the role of motherhood, preparation for labour and control in labour" $(p<0.05)$. While the thoughts about the wellbeing of self and baby subdimension scores of the group who became pregnant with infertility treatment were found to be higher, the identification with the role of motherhood, preparation for labour and control in labour subdimension scores were lower. There was no significant difference between the groups in terms of PSEQ total score and other subdimension scores $(p>0.05)$ (Table 3 )

\section{DISCUSSION}

In this study, in which the adaptation to the pregnancy of women who received infertility treatment and those who did not were compared, a significant difference was found between the two groups in terms of some descriptive characteristics. The mean age and marriage duration of the pregnant women who received infertility treatment were found to be higher than the other group. According to the American College of Obstetricians and Gynecologists(ACOG), age is a factor that has a stand-alone effect on fertility. Fertility rate decreases as women's age increases. The fertility of women decreases gradually, but significantly, starting from the age of 32 , and decreases faster after the age of $37(21)$. In line with the literature, it is expected that the age will be significantly higher in infertile women.

In pregnant women receiving infertility treatment, the rate of pregnant women with high school and lower education levels was found to be higher. According to the results of the Turkish Statistical Institute (2021), $99.4 \%$ of women using the internet have a university or higher education level (22). Since the data in this study were collected online, the majority of the participants were expected to have a high level of education. On the other hand, the rate of having a high school or lower education level was found to be significantly higher in pregnant women who received infertility treatment than other pregnant women. Given that infertility is an important problem affecting women's health, it is thought that women with all education levels can use the internet for this purpose. The number of multiple pregnancies, number of two or more pregnancies and miscarriages were found to

Table 3. Comparison of PSEQ total and subdimension scores of pregnant women who received infertility treatment and those who did not

\begin{tabular}{|c|c|c|c|c|}
\hline & $\begin{array}{l}\text { Not Receiving Infertility } \\
\text { Treatment (n:123) }\end{array}$ & $\begin{array}{l}\text { Receiving Infertility } \\
\text { Treatment (n:51) }\end{array}$ & Statistics & \\
\hline PSEQ and Subdimensions & 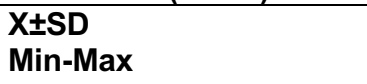 & $\begin{array}{l}\text { X } \pm \text { SD } \\
\text { Min-Max }\end{array}$ & $\mathbf{Z}^{*}$ & $\mathbf{p}$ \\
\hline PSEQ Total Score & $\begin{array}{l}139.10 \pm 28.15 \\
95-222\end{array}$ & $\begin{array}{l}135.90 \pm 19.50 \\
96-183\end{array}$ & -.109 & 0.913 \\
\hline $\begin{array}{l}\text { Subdimensions } \\
\text { Thoughts about the wellbeing of } \\
\text { self and baby }\end{array}$ & $\begin{array}{l}21.41 \pm 6.36 \\
10-35\end{array}$ & $\begin{array}{l}24.35 \pm 5.60 \\
11-39\end{array}$ & -2.605 & 0.009 \\
\hline Acceptance of pregnancy & $\begin{array}{l}22.23 \pm 7.07 \\
14-44\end{array}$ & $\begin{array}{l}20.94 \pm 5.92 \\
15-35\end{array}$ & -.978 & 0.328 \\
\hline Identification with motherhood role & $\begin{array}{l}24.60 \pm 6.42 \\
16-40\end{array}$ & $\begin{array}{l}21.11 \pm 3.42 \\
15-31\end{array}$ & -3.149 & 0.002 \\
\hline Preparation for labour & $\begin{array}{l}18.02 \pm 5.05 \\
10-33\end{array}$ & $\begin{array}{l}16.23 \pm 4.48 \\
10+26\end{array}$ & -2.080 & 0.038 \\
\hline Control in labour & $\begin{array}{l}20.10 \pm 5.02 \\
10-34\end{array}$ & $\begin{array}{l}18.19 \pm 3.94 \\
11-32\end{array}$ & -2.443 & 0.015 \\
\hline Relationship with mother & $\begin{array}{l}16.82 \pm 6.79 \\
10-40\end{array}$ & $\begin{array}{l}20.25 \pm 10.50 \\
10-40\end{array}$ & -1.056 & 0.291 \\
\hline Relationship with partner & $\begin{array}{l}15.88 \pm 6.35 \\
10-37\end{array}$ & $\begin{array}{l}14.80 \pm 6.52 \\
10-36\end{array}$ & -1.799 & 0.072 \\
\hline
\end{tabular}

X: Mean, SD: Standard Deviation, * Mann-Whitney U test, $p<0.05$ 
be higher in the group receiving infertility treatment, while the number of births of one or more and the number of living children was lower. It is noted in the literature similarly that the rates of multiple pregnancy after infertility treatment are high (23). The "Regulation on Assisted Reproductive Treatment Applications and Assisted Reproductive Treatment Centers (2014)" notes the requirement of transferring one embryo in the first and second application, two embryos in the third and subsequent applications, and a maximum of two embryos in all applications over 35 years of age (24). Because of these conditions, it is an expected result to have a high incidence of multiple pregnancy. Most women receiving infertility treatment have had previous pregnancy experiences but have ended in miscarriage. Similarly in the literature, Sunkara et al. (2014) reported that the risk of miscarriage is higher following IVF treatment in all age groups (25). The causes of infertility of women can also be associated with a large number of miscarriages.

In the study, pregnant women who received infertility treatment had more health problems were admitted to the hospital more during pregnancy compared to other pregnant women. Complications are more likely to occur in pregnancies resulted from infertility treatment. Miscarriage, ectopic pregnancy, multiple pregnancy, anemia, hypertensive diseases, Gestational diabetes mellitus (GDM), hyperemesis, premature birth, antepartum hemorrhages can be seen more frequently (26). Accordingly, the results of this study are in line with the literature.

In the study, although the adaptation of the pregnant women in both groups to pregnancy was similar, the adaptation with the sub-dimension of the thoughts about the wellbeing of self and baby of the women who became pregnant with infertility treatment was found to be lower. Pregnancies that occur as a result of infertility treatment are extremely stressful, although in some societies they are considered normal or low-risk $(27,28)$. Specific stressors of infertility treatment can last from the onset of pregnancy to childbirth (28). In the literature, Dornelles et al. (2014) stated that after infertility treatment, pregnant women mostly have fears and concerns about miscarriage, fetal death and baby birth with anomaly (7). Gourounti (2015) stated in a systematic review study in which he examined 20 studies, that after IVF, pregnant women had more pregnancy-related anxiety and less quality of life (29). In this study, it is thought that pregnant women receiving infertility treatment have more concerns about the health of both themselves and their babies due to reasons such as a difficult treatment process, health problems they have experienced and a history of miscarriage.

As another finding in the study, the adaptation to the pregnancy of women who received infertility treatment in the identification with the role of motherhood, preparation for labour and control in labour subdimensions were found to be higher. In the study of Furmli et al. (2019), women who became pregnant using assisted reproductive techniques reported lower rates of depressive symptoms, perceived stress, and general anxiety in the second trimester of pregnancy compared to women with spontaneous pregnancy (30). In his systematic review study Gourounti (2015) found that pregnant women after IVF had a more positive attitude towards pregnancy and were more attached to the fetus (29). In this study, it is thought that due to the dream of motherhood during the treatment process, pregnant women have prepared themselves for the pregnancy process and the role of motherhood. Identification of the motherhood role may be associated with the fact that pregnant women prepare themselves for labour more easily and are less afraid of labour.

\section{Limitations}

The study had some limitations. Firstly the numbers of pregnant women in the two groups who received and did not receive infertility treatment were not equal. Secondly, since the study was conducted only on pregnant women using the internet, there were more women with university degrees. Finally the results of the study could only be generalized to pregnant women who were social media users.

\section{CONCLUSION}

As a result of research, although the adaptation to the pregnancy of pregnant women in both groups was found to be similar, it can be said that pregnant women who received infertility treatment were more worried about their own and their baby's health, moreover, they had better at identification with the role of motherhood, they felt more prepared for labour and they had more control in labour.

In line with the study results, it is recommended to evaluate the concerns of pregnant women who become pregnant after infertility treatment about the wellbeing of self and baby and to plan interventions to reduce them, and to conduct studies with larger 
sample groups to examine the adaptation to the pregnancy of women who become pregnant after infertility treatment.

* This study was carried out as a master's thesis within the scope of Ege University Health Sciences Institute Women Health and Diseases Nursing Master's Program in 2021.

Acknowledgements: The authors would like to thank all the pregnant women.

Author contributions: Concept: H.A. Design: H.A., D.G.S. Data Collection and/or Processing: H.A. Analysis and/or Interpretation: H.A.,D.G.S. Writing and Literature Review: H.A.,D.G.S. Critical Review or Revision: D.G.S.

Conflict of Interest: No conflict of interest was declared by the authors.

Ethical Approval: Ethical approval was obtained from the Ege University's Medical Research Ethics Committee (Date:18.02.2021/No: 21-1.T/70) to conduct the study.

Funding: This research did not receive any specific grant from funding agencies in the public, commercial, or not-for-profit sectors.

Peer-review: Externally peer-reviewed.

\section{REFERENCES}

1. Monga M, Alexandrescu B, Katz SE, Stein M, Ganiats T. Impact of infertility on quality of life, marital adjustment, and sexual function. Urology 2004;63:126-130.

2. Akarsu RH, Beji NK. Spiritual and religious issues of stigmatization women with infertility: a qualitative study. J Relig Health 2021;60:256267.

3. Chandra A, Copen CE, Stephen EH. Infertility and impaired fecundity in the United States, 1982-2010: data from the National Survey of Family Growth. Natl Health Stat Report 2013;141-18.

4. Zhou Z, Zheng D, Wu H, Li R, Xu S, Kang Y et al. (2018). Epidemiology of infertility in China: a population-based study. BJOG 125:432-441.

5. Maharlouei N, Morshed Behbahani B, Doryanizadeh L, Kazemi M. Prevalence and pattern of Infertility in Iran: A systematic review and meta-analysis study. Women's Health Bulletin 2021;8: 63-71.

6. Sarac M, Koc I. Prevalence and risk factors of infertility in Turkey: evidence from demographic and health surveys, 1993-2013. J Biosoc Sci 2018;50:472-490.

7. Ozan YD, Duman M. The relationship between fertility adjustment and self-efficacy of women in the period of infertility treatment. The Journal of Gynecology - Obstetrics and Neonatology 2018;15:43-46.
8. Dornelles LMN, MacCallum F, Lopes RCS, Piccinini CA, Passos EP. The experience of pregnancy resulting from Assisted Reproductive Technology (ART) treatment: a qualitative Brazilian study. Women Birth 2016;29:123-127.

9. Massarotti C, Gentile G, Ferreccio C, Scaruffi P, Remorgida V, Anserini P. Impact of infertility and infertility treatments on quality of life and levels of anxiety and depression in women undergoing in vitro fertilization. Gynecol Endocrinol 2019;35:485-489.

10. Vitale SG, La Rosa VL, Rapisarda AMC, Lagana AS. Psychology of infertility and assisted reproductive treatment: the Italian situation. Journal Psychosom Obstet Gynecol. 2017;38:1-3.

11. Boivin J, Appleton TC, Batens P, Baron J, Bitzer $\mathrm{J}$, Corrigan $\mathrm{E}$ et al. Guidelines for counseling in fertility: outline version. Hum Reprod 2001;16:1301-1304.

12. Wegrezyn P, Szymusik I. Pregnancy in women after infertility treatment. Archives of Perinatal Medicine. 2014;20:73-77.

13. Çavuşoğlu İ, Beji NK. Assessment of quality of life and depression status of women who got pregnant after infertility treatment. Türkiye Klinikleri J Obstet Womens Health Dis NursSpecial Topics 2016;2:77-84.

14. Thomopoulos C, Tsioufis C, Michalopoulou H, Makris T, Papademetriou V, Stefanadis C. assisted reproductive technology and pregnancyrelated hypertensive complications: a systematic review. J Hum Hypertens 2013;27:148-57.

15. Jackson RA, Gibson KA, Wu YW, Croughan MS. Perinatal outcomes in singletons following in vitro fertilization: a meta-analysis. Obstet Gynecol 2004;103:551-563.

16. Da Silva S.G, Da Silveira MF, Bertoldi AD, Domingues MR, Dos Santos IDS. Maternal and child-health outcomes in pregnancies following Assisted Reproductive Technology (ART): a prospective cohort study. BMC Pregnancy and Childbirth 2020; 20:1-8.

17. Kiehl EM, Carson DK, Dykes AK. Adaptation and resiliency in Swedish families. Scand J Caring Sci 2007;21:329-37.

18. Başgöl Ş. Determination of adaptation to pregnancy among pregnancies after application of assisted reproduction treatment (dissertation). İstanbul, İstanbul University. 2018. 
19. Lederman RP, Lederman E. Dimensions of postpartum adaptation: comparisons of multiparas 3 days and 6 weeks after delivery. $\mathrm{J}$ Psychosom Obstet Gynaecol 1987;7:193-203.

20. Beydağ KD,Mete $S$. Validity and reliability study of the Prenatal Self Evaluation Questionnaire. Journal of Anatolia Nursing and Health Sciences 2008;11:16-24.

21. ACOG. Committee Opinon Number 589. 2014, March. https://www.acog.org//media/project/acog/acogorg/clinical/files/commit tee-opinion/articles/2014/03/female-age-relatedfertility-decline.pdf

22. TUiK. Information Technology Usage Survey 2020.

https://data.tuik.gov.tr/Bulten/Index?p=Hanehalki -Bilisim-Teknolojileri-(BT)-Kullanim-Arastirmasi2021-

37437\#: :text=T\%C3\%9C\%C4\%B0K\%20Kurum sal\&text=Hanehalk\%C4\%B1\%20bili\%C5\%9Fim \%20teknolojileri\%20kullan\%C4\%B1m\%20ara\% C5\%9Ft\%C4\%B1rmas\%C4\%B1,y\%C4\%B1I\%2 $0 \% 90 \% 2 \mathrm{C} 7 \% 20$ idi.

23. Güler AE, Pehlivan H, Korucuoğlu Ü, Çakmak B, Şahin S, Biri A. Perinatal Results of Assisted Reproductive Technique and Spontaneous Twin Pregnancies. 2016;8:256-62.

24. Regulation on Assisted Reproductive Treatment Applications and Assisted Reproductive Treatment Centers 2014. https://www.mevzuat.gov.tr/mevzuat?MevzuatN o=20085\&MevzuatTur=7\&MevzuatTertip=

25. Sunkara SK, Maheshwar YH, Tohum $P$, Coomarasamy A. Association between response to ovarian stimulation and miscarriage following Ivf: an analysis of 124351 IVF pregnancies. Human Reprod 2014;29:1218-1224.

26. Yanıkkerem E, Kavlak O, Sevil Ü. Infertile couple's problems and nursing approach. Journal of Anatolia Nursing and Health Sciences 2008;11:112-121.

27. Rooney KL, Domar AD. The relationship between stress and infertility. Dialogues Clin Neurosci 2018; 20:41-47.

28. Warmelink JC, Meijer JM, Mulder N, Mulder S, Van Lohuizen MT. Perception of the psychosocial aspects of subfertility by parents following successful medically assisted conception: a qualitative study. Open Journal of Obstetrics and Gynecology 2016;6:830-845.
29. Gourounti K. Psychological stress and adjustment in pregnancy following assisted reproductive technology and spontaneous conception: A systematic review. Women \& Health 2016;56:98-118.

30. Furmli $H$, Seeto RA, Hewko SL, Dalfen A, Jones CA, Murphy KE, Bocking A. Maternal mental health in assisted and natural conception: a prospective cohort study. J Obstet Gynaecol Can 2019; 41:1608-1615. 